\title{
Poder y sacrificio. Los nuevos discursos de la empresa. Luis Enrique Alonso y Carlos Jesús Fernández Rodríguez. Madrid: Siglo XXI, 2018.
}

\author{
Maria Medina-Vicent \\ Universitat Jaume I \\ medinam@uji.es
}

Poder y sacrificio. Los nuevos discursos de la empresa viene a completar el extenso trabajo de los sociólogos Luis Enrique Alonso y Carlos Jesús Fernández Rodríguez en anteriores obras como La financiarización de las relaciones salariales: una perspectiva internacional (Catarata, 2012), y Los discursos del presente. Un análisis de los imaginarios sociales contemporáneos (Siglo XXI, 2013). En esta obra ambos autores emprenden la tarea de diseccionar las principales prácticas discursivas y reconceptualizaciones sobre las que se sostiene la lógica neoliberal de nuestro tiempo, que actúan como métodos disciplinarios para la mercantilización de las estructuras estatales y las vidas de los individuos.

En el primer capítulo de la obra los autores abordan "Ios discursos del management desde una perspectiva crítica" (pp. 23-52). Su reflexión se centra en torno al poder del discurso de la gestión a la hora de configurar las imágenes de la empresa en el imaginario social y su influencia en la determinación de los valores morales dominantes en la gestión empresarial. A través de la literatura del management dichos principios son divulgados de forma acrítica y masiva, hecho que convierte a esta literatura en un objeto de estudio crucial para identificar la evolución de los discursos de la gestión a lo largo de las décadas.

Así pues, el análisis realizado circunscribe los cambios que se dan en esta literatura desde finales del siglo xIx con las teorías del darwinismo social, pasando por la era de la gran corporación y su paradigma racional, hasta la época de incertidumbre actual que demanda flexibilidad y adaptación por parte de gobiernos, empresas y población. Desde su punto de vista, dicha evolución es una muestra de que "las crisis de rentabilidad del sistema capitalista, ante las transformaciones de los mercados, son las que marcan los cambios organizativos y su consiguiente discurso" (p. 43). Por tanto, el discurso de la gestión difundido a través de esta literatura está sujeto a las sucesivas crisis y necesidades cambiantes de los mercados, es decir, se adapta a los requerimientos discursivos del sistema y difunde las consiguientes prescripciones entre la clase directiva y la población general.

Uno de los temas de mayor interés en la literatura gerencial de la última década, azotada por las problemáticas derivadas de la globalización y las crisis financieras, es el de la innovación, tema en el que se centra el segundo capítulo titulado "Innovación social. Luces y sombras de un concepto" (pp. 53-74). La consolidación del régimen de producción posfordista trae consigo la puesta en valor de un conjunto de valores que pasan a formar parte de los discursos sociales, como el que se refiere a la concepción del trabajador como un sujeto innovador, creador, emprendedor, visionario, etc. Se trata de un discurso que tiene por objeto convertir a los trabajadores en empresarios de sí mismos. Dentro de esta lógica posmoderna, la innovación social pierde su sentido primigenio de adquisición de derechos sociales y empieza a entenderse como un impulso a la sociedad del conocimiento.

Al mismo tiempo, resulta central situar dicha reconceptualización de la innovación social en un contexto de "financiarización y crisis del empleo" (pp. 75-102). Tal y como indican Alonso y Fernández Rodríguez, la financiarización supone el "incremento 
del poder financiero en lo económico, lo político y lo social" (p. 77), es decir, la lógica financiera pasa a formar parte de las instituciones públicas y privadas a la hora de determinar qué es lo legítimo o real. Dicho concepto permite a los autores desgranar la verdadera lógica que subyace a la reciente crisis, que parece haber aumentado el poder de la economía financiera en lo social, hecho que ha promovido la desregulación y la flexibilización de las relaciones laborales bajo el discurso del sacrificio. Así pues, mediante su análisis, se desvela que la crisis financiera actual es más un proceso de gubernamentalidad y ajuste disciplinario de los cuerpos a la producción del valor mercantil, que un fenómeno de estricta naturaleza económica. Esta visión es sumamente importante para poner en evidencia que, en esta nueva lógica financiera, el peso de la responsabilidad última de los problemas económicos recae en hombros de la ciudadanía, mientras que las instituciones gubernamentales se doblegan frente a los dogmas del mercado financiero. Un ejemplo claro lo encontramos en el momento en que estados como el español se convirtieron en "salvavidas" de la banca, mientras miles de familias veían truncados sus proyectos de vida.

Desde el punto de vista de los autores, este contexto de crisis financiera sería un proceso que desvela las relaciones de dominación que vertebran la sociedad, cuestión que abordan en el cuarto capítulo ("Debemos aplacar a los mercados. El espacio del sacrificio en la crisis financiera actual", pp. 103-134). En este contexto donde se produce un descenso en las políticas sociales frente a los intereses del mercado financiero, las relaciones se basan en el sacrificio de muchos para el bienestar de unos pocos: las élites empresariales. La crisis serviría para reforzar las reglas del juego, ya que contiene una condición performativa que conforma el sentido del mundo y condiciona las subjetividades individuales. Es decir, los discursos producidos durante la crisis, al ser incorporados por los individuos y las instituciones, sirven para situar la responsabilidad de su salida en las decisiones individuales. De esta manera, se desposee a la ciudadanía a través de la producción de miedos que actúan como método disciplinario para establecer los límites de la identidad de cada cual y las posi- bilidades de construir un proyecto de vida de futuro con garantías.

Dichas subjetividades estarán ahora sujetas a la lógica de la competitividad mercantil y el economicismo que recurre a la deuda para reconceptualizar las relaciones sociales asimétricas basadas en la violencia. Esta reconceptualización es abordada por parte de los autores a través del pensamiento de René Girard y su teoría del chivo expiatorio como salida de la crisis. A través de estas ideas, se sostiene que en el caso español los chivos expiatorios para salir de la crisis financiera han sido numerosos: salarios y contratos de empleados públicos y privados, derechos laborales y sindicales históricos, gasto sanitario y educativo, y personas que lo han perdido todo (p. 127). El sacrificio, señalan, se ha convertido en una salida de la crisis que tiene un precio muy alto, esto es, se sacrifican las clases más desfavorecidas, los trabajadores del sector público y los servicios públicos en sí mismos en pro de una mercantilización aún más dura de todos los ámbitos de la vida.

En esta transformación de las identidades individuales y colectivas a merced de los vaivenes del mercado ejercen un gran papel "la burocracia neoliberal y las nuevas funciones de las normas" (pp. 135-160). La burocracia ha sido un aspecto central de estudio en el ámbito económico y político, sin embargo, su papel dentro de estos espacios ha variado históricamente hasta llegar a la realidad de nuestros días. En la época del capitalismo fordista, la burocracia era un elemento clave de la gestión empresarial y los managers eran concebidos de forma mayoritaria como grandes burócratas. Pero con la llegada del capitalismo neoliberal, la libertad, la creatividad, la innovación y la eliminación de los procesos burocráticos de la vida económica se pondrán en valor. Se tratará de eliminar las trabas para las empresas, reducir el papel del Estado del Bienestar, y construir empleados emprendedores, innovadores y que aprovechen las oportunidades. Este nuevo gerencialismo se alza libre frente a la rigidez de la burocracia y la jerarquía anteriores, poniendo el énfasis en las redes y la innovación. Esta nueva lógica neoliberal se traslada también a las estructuras estatales, pasando de un Estado del Bienestar a un Estado manager que reproduce las lógicas mercantiles convirtiendo 
la vulnerabilidad, la disponibilidad constante y la adaptación a los cambios del mercado en principios rectores de la vida.

Sin embargo, la paradoja de este proceso, tal y como señalan los autores, es que este esfuerzo neoliberal por garantizar un entorno seguro para la inversión privada que en principio huiría de la burocracia fordista, ha acabado por producir una mayor burocratización en los estados y los individuos. Y es que, la época neoliberal precisa de sistemas de burocratización mucho más sofisticados que los que se daban en épocas anteriores, se trata de sistemas que garantizan la gestión pública como privatización, y la gestión de uno/a mismo/a como empresa. Una burocracia que se centra en el control de la población para garantizar la expansión del espíritu neoliberal y la lógica mercantil. De este modo, se genera un autocontrol de cada individuo en su accionar diario que garantiza la completa disponibilidad de dichos sujetos a los cambios y sucesivas crisis de los mercados.

Dicho autocontrol tiene mucho que ver con la imagen social proyectada sobre los gerentes y sus cambios a lo largo de la historia, una cuestión que se aborda en el capítulo "El nuevo debate sobre el gerencialismo. ¿Innovación creativa 0 maquiavelismo financiero?" (pp. 161-186). La incorporación de lógicas de autocontrol por parte de los individuos adquiere sentido en gran parte en el modelo social de gerente que se difunde y que se dibuja como espejo en el que mirarse. Sin embargo, no es la misma imagen la que predomina hoy en día que la que encontramos a mediados del siglo xx. En este momento autores como James Burnham reflexionaron en torno a la visión maquiavélica de los directivos, es decir, el auge de los managers concebido como una revolución social que venía a desafiar al capitalismo burgués. Dicho desafío radicaba en el control de los medios de producción por parte de los directivos, que se convertirían en la nueva clase social explotadora. Así, según Burnham, el poder de esta nueva sociedad se ejercería desde el maquiavelismo de los directivos.
Esta imagen se empieza a trastocar en los años setenta, tras diversos acontecimientos y procesos sociales de gran envergadura como la crisis del petróleo y la radicalización del movimiento obrero. En este contexto la visión de los gerentes es más bien positiva, se trata de modelos de conducta a los que equipararse caracterizados por la acción carismática y la virtud del liderazgo eficiente. Sin embargo, con la crisis financiera del año 2007 se pone en cuestión la figura de los ejecutivos 0 managers y las implicaciones éticas de su accionar, volviendo a una visión maquiavélica de los mismos. Así, tal y como afirman los autores, si bien estas malas prácticas serán condenadas por parte de la población, realmente esta condena no implica una crítica profunda a la lógica neoliberal, sino al contrario, paradójicamente el discurso neoliberal parece fortalecerse frente al resurgimiento de una concepción maquiavélica de los gerentes y una culpabilización creciente de la sociedad.

En resumen, la obra ante la que nos encontramos desvela la influencia de los discursos del gerencialismo en la gestión pública y la vida de los individuos en la actualidad. Así pues, la labor emprendida por los sociólogos Luis Enrique Alonso y Carlos Jesús Fernández Rodríguez conlleva un acertado diagnóstico de las contradicciones de nuestro tiempo, de los discursos que perpetúan las injusticias y de la primacía de los criterios mercantiles en los gobiernos y la vida de los individuos. A través de una reflexión siempre atenta a la evolución de las sociedades y la economía, los autores identifican un peligroso proceso referido al descenso en las políticas sociales y la pérdida en la calidad de vida democrática de nuestras sociedades. En definitiva, la profunda reflexión realizada en Poder y sacrificio. Los nuevos discursos de la empresa consigue deshilar la maraña de hilos discursivos sobre los que se sustenta la precariedad multidimensional actual, así como los perversos juegos discursivos que se llevan a cabo para incorporar la idea del sacrificio como bandera de nuestras vidas, gobernadas por la lógica del poder empresarial. 